\title{
Türkiye'de farklı yörelerde bulunan kolemanit minerallerinin fiziksel, kimyasal ve termal özelliklerinin tayini
}

\author{
Determination of physical, chemical and thermal properties of colemanite minerals in \\ different regions of Turkey
}

\author{
Dilek ŞENOL ARSLAN"1,a \\ ${ }^{1}$ Abdullah Gül Üniversitesi, Mühendislik Fakültesi, Nanoteknoloji Mühendisliği Bölümü, 38380, Kayseri
}

• Geliş tarihi / Received: 02.05.2021• • Düzeltilerek geliş tarihi / Received in revised form: $13.08 .2021 \quad$ • Kabul tarihi / Accepted: 24.08 .2021

\section{Öz}

Bu çalışmada, Türkiye bor rezevlerinin yaklaşı \% 76 'sını oluşturan bilimsel ve teknolojik gelişmeler sonucu elde edilen uygulamalarda sıklıkla kullanılan, önemli bir bor minerali olan kolemanit kullanılmıştır. Bu kapsamda, ilk önce kolemanit minerali hakkında detaylı bir literatür taraması yapılmıştır. Türkiye'de toplam dört yörede bulunan kolemanit (Kestelek, Emet (Hisarcık, Espey), Bigadiç yöreleri) numunelerinin yapısal ve karakteristik özellikleri (X-Ray Difraksiyon), ICPMS (İndüktif Eşleşmiş Plazma, ICP ve Kütle Spektrometresi, MS), TG-DTA (Termogravimetrik ve Diferanasiyel termal analiz), FT-IR (Kızılötesi (IR) absorbsiyon spektroskopisi) analizleri ile belirlenmiştir. Elde edilen sonuçlar doğrultusunda saf kolemanit kristallerinin minerolojik, kimyasal ve termal özellikleri tespit edilip, numuneler arasındaki benzerlik ve farklılıkların ortaya konulması amaçlanmıştır.

Anahtar kelimeler: Bigadiç, Bor, Espey, Hisarcık, Karakterizasyon, Kestelek, Kolemanit

\begin{abstract}
In this study, colemanite is an important boron mineral which constitutes about $76 \%$ of Turkey's boron reserves, is frequently used in applications obtained as a result of scientific and technological developments. In this context, a detailed literature survey was carried out colemanite minerals. Characteristic and structural features of the colemanite samples offour different regions (Kestelek, Emet (Hisarcık, Espey), Bigadiç regions) were determined by analyzes such as X-Ray Diffraction (XRD), Inductively Coupled Plasma, ICP and Mass Spectrometry, MS (ICP-MS), Thermogravimetric and Differential thermal analysis (TG-DTA), and Fouier Transform Infrared Spectroscopy (FT-IR) methods. In line with these findings, the mineralogical, chemical and thermal properties of pure colemanite crystals were determined and the similarities and differences between the samples were revealed.
\end{abstract}

Keywords: Bigadiç, Boron, Espey, Hisarcı, Characterization, Kestelek, Colemanite

\footnotetext{
${ }^{* a}$ Dilek ŞENOL ARSLAN; dilek.senol@agu.edu.tr, orcid.org/0000-0001-9639-2843
} 


\section{Giriş}

Doğada bulunan bor mineralleri yapılarındaki $\mathrm{Ca}$, $\mathrm{Na}$ ve $\mathrm{Mg}$ elementlerine göre sınıflandırılmaktadırlar. $\mathrm{Na}$ kökenli olan bor minerallerine "tinkal" (boraks), $\mathrm{Ca}$ kökenli olanlara "kolemanit" ve Na-Ca kökenli olanlara ise "üleksit" denilmektedir (Helvacı, 2003; Demirtaş, 2006). Genel olarak doğada yaklaşık 230 çeşit bor minerali olduğu bilinmektedir. Ticari öneme sahip olan bor mineralleri $\% \mathrm{~B}_{2} \mathrm{O}_{3}$ (borik oksit) oranına göre belirlenir. $\mathrm{Bu}$ açıdan en önemli bor mineralleri; boraks $\left(\mathrm{Na}_{2} \mathrm{~B}_{4} \mathrm{O}_{7} \cdot 10 \mathrm{H}_{2} \mathrm{O}\right)$, kolemanit $\left(\mathrm{Ca}_{2} \mathrm{~B}_{6} \mathrm{O}_{11} .5 \mathrm{H}_{2} \mathrm{O}\right)$, üleksit $\left(\mathrm{NaCaB}_{5} \mathrm{O}_{9} .8 \mathrm{H}_{2} \mathrm{O}\right)$, kernit $\quad\left(\mathrm{Na}_{2} \mathrm{~B}_{4} \mathrm{O}_{7} .4 \mathrm{H}_{2} \mathrm{O}\right)$, probertit $\left(\mathrm{NaCaB}_{5} \mathrm{O}_{9} .5 \mathrm{H}_{2} \mathrm{O}\right)$, szaybelit $\left(\mathrm{MgBO}_{2}(\mathrm{OH})\right)$, pandermenit $\quad\left(\mathrm{Ca}_{4} \mathrm{~B}_{10} \mathrm{O}_{19} .7 \mathrm{H}_{2} \mathrm{O}\right)$, borasit $\left(\mathrm{Mg}_{3} \mathrm{~B}_{7} \mathrm{O}_{13} \mathrm{Cl}\right)$ ve hidroborasittir $\left(\mathrm{CaMgBO}_{11} .6 \mathrm{H}_{2} \mathrm{O}\right)$ (Habashi, 1997; Woods, 1994; Kar vd., 2006; Erdoğan vd., 1998). Bor cevherleri (konsantre bor) fiziksel işlemlere tabi tutularak zenginleştirir, daha sonra rafine edilerek farklı bor kimyasallarına dönüştürülür. Genel olarak bu ürünlerin tamamı "Bor" olarak adlandırılmaktadır (Eti Maden İşletmeleri Genel Müdürlüğü 2016, Yigitbasioglu 2014).

Bor mineralleri içerisinde en yaygın olanı kolemanittir. Türkiye'de özellikle Emet, Bigadiç ve Kestelek yataklarında, Dünya'da ise Amerika Birleşik Devletleri (A.B.D)'de bulunur. Kolemanit, monoklinik sistemde kristalleşen, sertliği 4-4.5, özgül ağırlığ $2.42, \mathrm{~B}_{2} \mathrm{O}_{3}$ içeriği
\%50.8 olan, suda yavaş asitte $(\mathrm{HCl})$ hızlı çözünen bir bor mineralidir (Yigitbasioglu, 2014; Helvac1 2015). Kolemanit yataklarının birçoğunda, içinde boşluk bulunan ve kil mineralleri içerisinde gömülmüş yumru ve patates şeklindeki bantlar halinde bulunur. Yumru ve patates içerisindeki kolemanit genellikle beyaz, şeffaf cams1 parlaklıkta ve renksizdir, bir kısmının içerisinde ise mavi renkli, uzun, ortorombik sölestin kristalleri yer alır. Nadir olarak kompakt ve sütunsal yapı gösterir. Kolemanitin içerisinde bulunan ve kalitesini düşüren gang mineralleri ise; arsenik, daha çok örpiment $\left(\mathrm{As}_{2} \mathrm{~S}_{3}\right)$ ve realgar $\left(\mathrm{As}_{2} \mathrm{~S}_{2}\right)$ dır.

\subsection{Türkiye'deki kolemanit minerallerinin jeolojisi}

Türkiye'de bilinen kolemanit yatakları Batı Anadolu bölgesinde yer almaktadır. Bu yataklar volkanik aktivite ile playa-göl tortulları içerisinde oluşmuştur (Helvac1, 2004a). Miyosen volkano sedimenter tortullar içerisinde yer alan bu borat yataklarının litolojisinin birbirinden farklılıklar göstermesine karşın, çoğunlukla kireçtaşı, çakıltaşı, kiltaşı, kumtaşı, tüf, tüfit, ve marn ile arakatmanlı olarak çökelmiştir (Helvac1, 2004b). Türkiye'deki kolemanit yatakları; Bigadiç, Emet ve Kestelek yörelerine ait kolemanit rezervlerinin konumu, borat birimleri ve Neojen stratigrafik kesitleri Şekil 1'de sunulmuştur. Bu bölgede yeralan Miyosen yaşlı borat yataklarının, genellikle yüksek silika içerikli olduğu ve yüksek miktarda $\mathrm{B}$, $\mathrm{As}, \mathrm{F}, \mathrm{Li}, \mathrm{Sb}, \mathrm{S}$ ve $\mathrm{Pb}$ gibi volkanik ürünler içerdiği bilinmektedir (Erdem, 2010; Helvac1 2015).
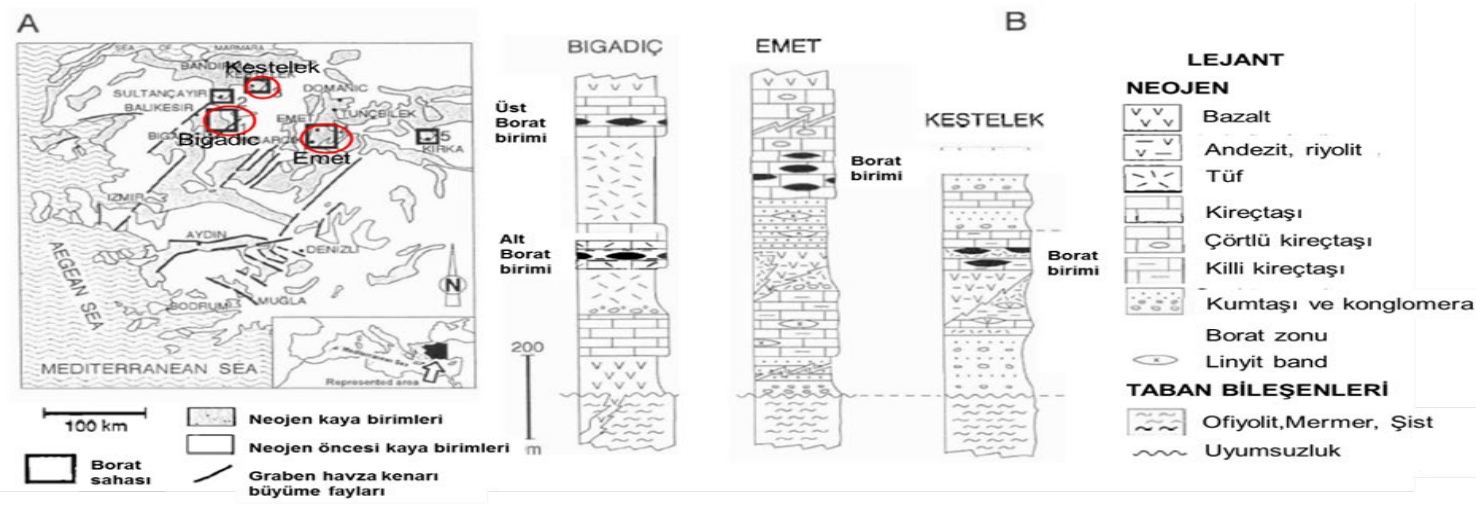

Şekil 1.(a) Türkiye'deki kolemanit rezervlerinin konumu (b) Neojen stratigrafik kesitler- Bigadiç, Emet ve Kestelek yörelerine ait borat birimleri (Helvaci ve Orti 1998).

Şekil 1'de görüldüğü gibi, bor çökelimi için uygun olduğu düşünülen Neojen havzalarında oluşur. Borat yatakları iki kalın tüf tabakası tarafindan iki birime (alt ve üst boratlar) ayrılmıştır. Kolemanit borat birimlerinde baskın minerallerdir. Bigadiç boratları kil, kireçtaşı ve tüf içerisine gömülmüşlerdir. Emet havzasında bulunan borat birimi miyosen tortulları içerisinde kil, tüf ve marn ara katlıdır. Diğer taraftan Kestelek havzasında bulunan borat birimi ise miyosen tortulları içerisinde kil, marn, kireçtaş1, tüflü kireçtaş1 ve tüf ara katlıdır (Helvaci, 1977; Helvaci ve Orti 1998; Dill vd., 2015). Kolemanit minerali ve beraberinde bulunan bazı gang minerallerinin görselleri Şekil 2'de sunulmuştur. 

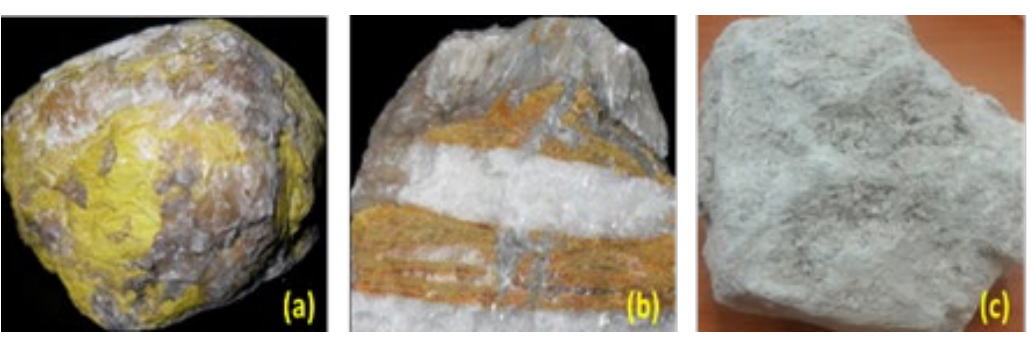

Şekil 2. (a) Kolemanit içine gömülmüş orpiment (b) kolemanit içine gömülmüş realgar (Helvac1, 2005) (c) kolemanit ile beraber bulunan kalsit ve kil mineralleri.

Genel olarak borat yataklarında farklı oranlarda kalsit, jips, dolomit, sölestin, anhidrit, realgar, orpiment mineralleri bulunmaktadır. Bu mineraller baskın olarak Emet yataklarında mevcuttur, ayrıca bu yörede Ca-As boratların varlığı da bilinmektedir (Helvac1, 2008).

\subsection{Bor minerallerinin kullanım alanları}

Günümüzde, neredeyse 250 farklı ürün üretiminde farklı oranlarda kullanılan bor minerali, geleceğin madeni olarak bilinmektedir (Bilgiç ve Dayık 2013).

Kullanım alanları ve üretim teknolojileri dikkate alındığında bor mineralleri genel olarak iki grupta incelenebilir:

1.Yaygın kulanım alanına sahip olan bor mineralleri ve ticari boratlar.

2. Kısıtlı miktarlarda üretilen ve özel tüketim alanları olan özellikli bor ürünleri.

Birçok bor minerali (kolemanit, üleksit, tinkal) zenginleştirilerek doğrudan ara madde olarak kullanılmasına rağmen, yaygın kullanım alanına sahip olan ticari boratlar ise kimyasal üretim teknolojileri ile üretilmektedir (Eti Maden İşletmeleri Genel Müdürlüğü, 2009; Woods, 1994). Bor bileşikleri endüstride yaygın ve çeşitli kullanım alanlarına sahiptir. Son yıllardaki teknolojideki gelişmeler özellikli bor bileşiklerine duyulan talebin artmasını sağlamıştır. Ayrıca, özellikli bor bileşiklerinin, bor tüketiminde toplamda \%25'lik paya sahip olduğu da bilinmektedir (Woods, 1994, Kalafatoğlu ve Örs 2003; Kılınç vd., 2001). Ham bor ürünlerinin (özellikle kolemanit ve tinkal) \%90'1 borik asit, boraks dekahidrat ve pentahidrat gibi rafine bor ürünlerinin üretiminde kullanılmaktadır (Güyagüler 2001). Bunların yansıra kolemanit, farklı amaçlara yönelik olarak; cam elyafi (fiberglas), nükleer uygulamalar, borosilikat cam ve metalürjide birçok alanda sıklıkla kullanılmaktadır. Özellikle, borlu çelik üretiminde fluorit yerini alabilen üleksit ve kolemanit mineralleri tercih edilmeye başlanmıştır (Poslu ve Arslan 1995; Yildiz, 2004).

Kolemanit mineralinin kullanım alanının çeşitliliği ve elde edilen ürünlerin proses aşamasında gang minerallerinden kaynaklı mineralojik, kimyasal ve termal sorunları dikkate alındığında, çalışma öncesi yapılacak karakterizasyon çalışmalarının büyük önem taşıdığı görülmektedir. Bu çalışma ile dört farklı yöreye ait kolemanit (Kestelek, Emet (Hisarcık, Espey), Bigadiç yöreleri) numunelerinin karakteristik özellikleri (X-Ray Difraksiyon), ICPMS (İndüktif Eşleşmiş Plazma, ICP ve Kütle Spektrometresi, MS), TGDTA(Termogravimetrik ve Diferanasiyel termal analiz), FT-IR (Kızılötesi (IR) absorbsiyon spektroskopisi) gibi analizlerle belirlenmiştir. Elde edilen sonuçlar ile birlikte saf kolemanit kristal numuneleri arasındaki benzerlik ve farklı1ıkların ortaya konulması amaçlanmıştır.

\section{Materyal ve metot}

\subsection{Malzeme}

$\mathrm{Bu}$ çalışmada kullanılan numuneler: Kütahya, Emet'ten (Espey ve Hisarcık) ilçelerindeki ocaklardan seçilmiştir, Bursa, Kestelek ve Balıkesir, Bigadiç ilçelerinden ise Eti Maden İşletmeleri tarafından temin edilmiştir. Deneylerde kullanılan saf kolemanit kristalleri Şekil 3'de sunulmuştur. 

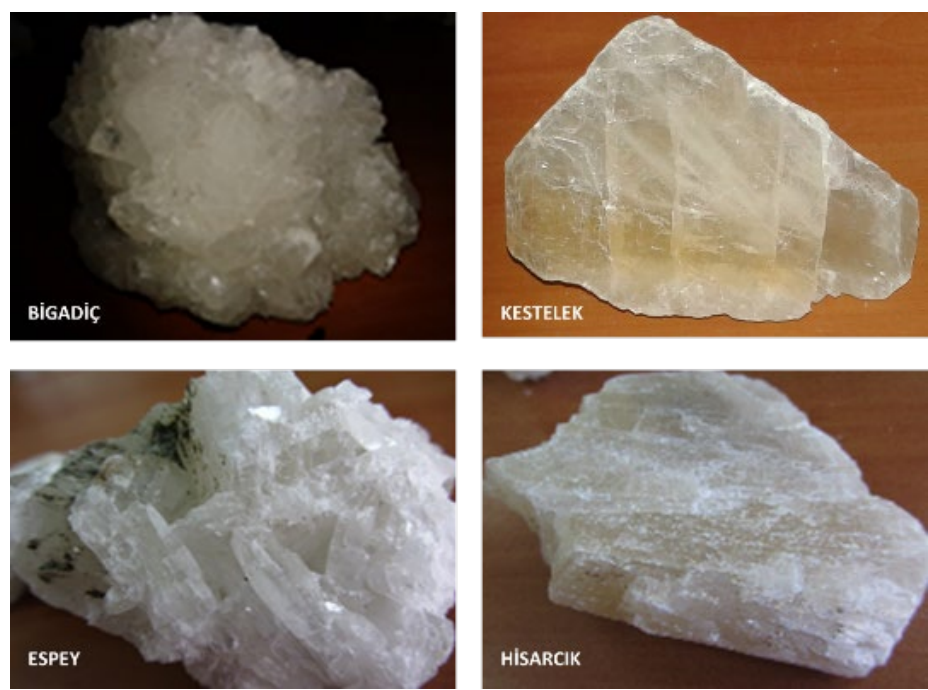

Şekil 3. Bigadiç, Kestelek, Espey ve Hisarcık yörelerinden temin edilen deneysel çalışmalarda kullanılan kolemanit kristalleri.

Şekil 3’te görüldüğ̈̈ üzere, aynı kimyasal bileşime sahip dört farklı yöreye ait saf kolemanit minerali incelendiğinde; kristal oluşumu ve şekli, renk, parlaklık, sertlik ve klivaj gibi fiziksel özellikleri açısından birbirinden farklı olduğu görülmektedir.
Tüm deneysel çalışmalar ve ölçümlerde kullanılan numunelerin hazırlanması aşamasında herhangi bir konteminasyon olmaması için tüm süreçler titizlikle yürütülüp, aşamalar Şekil 4'teki akım şemasında sunulmuştur.

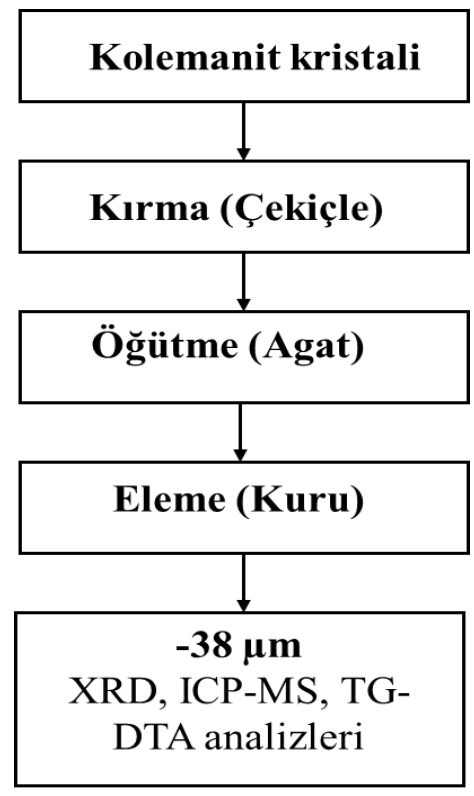

Şekil 4. Deneysel çalışmalarda kullanılan toz numunelerin hazırlık şeması.

Şekil 4'teki akım şemasından anlaşıldığı üzere, dört farklı yöreden temin edilen kolemanit kristalleri ilk olarak çekiçle boyut küçültme işlemi gerçekleştirilmiştir. Daha sonra agatta öğütülmüştür. Son olarak, ögütülen tüm kolemanit kristal numuneleri kuru olarak elenerek istenilen $38 \mu \mathrm{m}$ boyut fraksiyonu elde edilmiștir. 


\section{Bulgular ve tartışma}

\subsection{X-ışııı difraksiyon (XRD) analizleri}

Karakterizasyon çalışmaları kapsamında ilk önce XRD ile dört farklı yöreye ait kolemanit
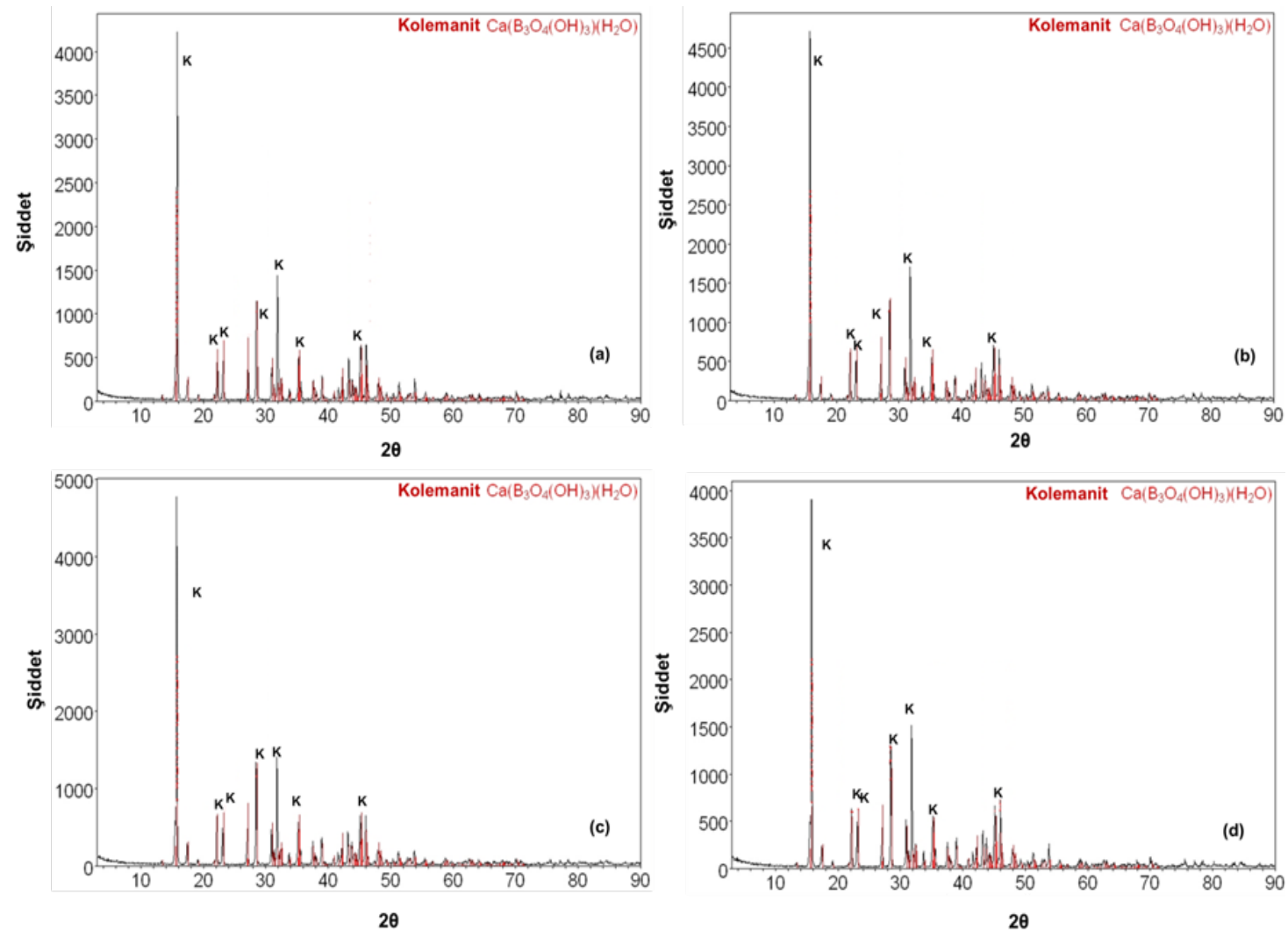

Şekil 5. (a) Bigadiç (b) Kestelek (c) Espey

(d) Hisarcık kolemanit kristallerinin XRD sonuçları.

Şekil 5'te dört farklı yöreye ait XRD analizleri incelendiğinde; tüm piklerin sadece kolemanit mineraline ait olduğu anlaşılmıştır. Tüm numunelerin saf olup herhangi bir istenmeyen (gang) mineral içermediği anlaşılmıştır. Şekil 6.'da ise aynı yörelerdeki kolemanit cevheri ve kolemanit atığına ait literatürde yer alan bazı çalışmaların XRD analizleri sunulmuştur.

Şekil 6 (a)'da Emet kolemanit cevheri ile yapılan XRD analizinde kolemanit ile birlikte arsenik bileșikleri olan realgar, orpiment, dimorfit, montmorillonit ve magnezyumca zengin klorit grubu mineralli olan klinoklor tespit edilmiştir. numunelerinin mineralojik analizi ile saflık derecesinin belirlenmesi amaçlanmıştır. Elde edilen sonuçlar Şekil 5'de sunulmuştur. (b)'de ise Bigadiç kolemaniti konsantratör atığının XRD analizinde kolemanit ile birlikte kalsit, dolomit ve kuvars mineralleri tespit edilmiştir. (c) ve (d)'de ise sırasıyla Hisarcık ve Espey açık ocaklarından alınan cevher numunelerinin analizi sonucunda; Hisarcık kolemanitinde kalsit, kuvars, feldispat, kristobalit, plajiyoklas, realgar, orpiment, selestit, smektit, illit, kil, kalkerli kil, tüfit bulurken Espey ocağında kalsit, kuvars, feldispat, kahnit, plajiyoklas, simektit, illit, klorit, kaolinit, kil, kalkerli kil tespit edilmiştir (Çelikoyan Kuşkay, 2010; Colak vd., 2000). 

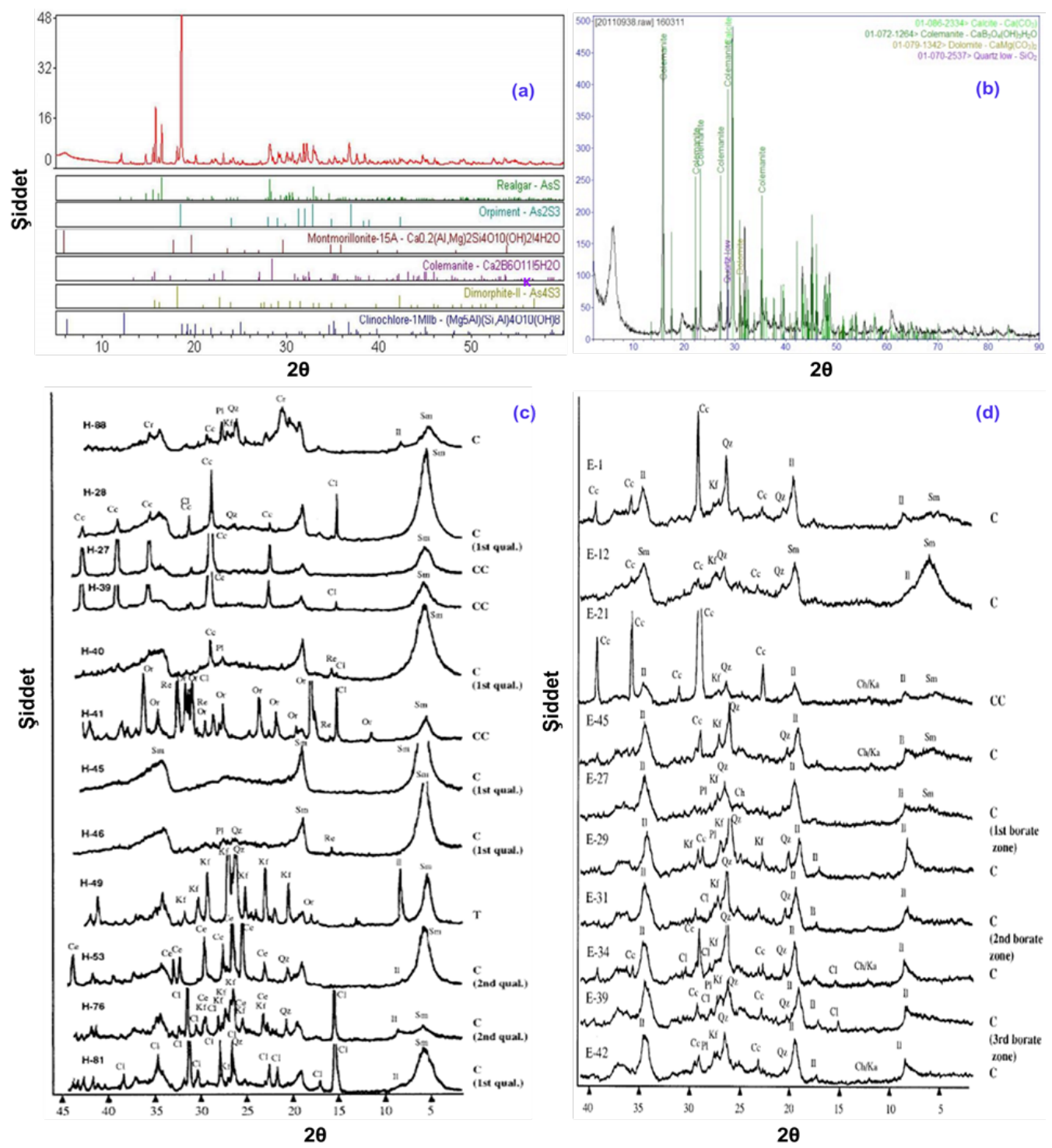

Şekil 6. (a) Emet kolemanit cevheri XRD analizi (Karaaağlıŏlu, 2016) (b) Bigadiç kolemaniti konsantratör atığının XRD analizi (Bayca vd., 2014) (c) Hisarcık kolemaniti açık ocak madeninden seçilen cevher numunelerinin XRD analizi. (Cc: kalsit, Qz:Kuvars, Kf: K-zengin feldispat, Cr: kristobalit, Pl: plajiyoklas, Cl: kolemanit, Re: realgar, Or: orpiment, Ce: selestit, Sm: Smektit, Il: illit, C: kil, CC: kalkerli kil, T: tüfit)(Colak vd., 2000) (d) Espey kolemaniti açık ocak madeninden seçilen cevher numunelerinin XRD analizi (Cc: kalsit, Qz:Kuvars, Kf: K zengin feldispat, Ca: kahnit, Pl: plajiyoklas, Cl: kolemanit, Sm: simektit, Il: illit, Klorit, Ka: kaolinit).C: kil, CC: kalkerli kil (Colak vd., 2000).

\subsection{ICP/MS analizleri}

Dört farklı yöreye ait kolemanit numunelerinin oluştuğu yatağın jeolojik, mineralojik ve oluşumundaki farklılıklardan dolayı deneylerde kullanılan tüm kolemanit numunelerinin ana ve eser elementleri arasındaki benzerlik ve farklılıkları tayin etmek için ICP/MS analizi yapılmıştır.

Tüm deneylerde kullanılan kolemanit kristallerinin çözeltiye alınarak bileşenlerinin çözeltiye geçmesi ile elde edilen sonuçlar Tablo 1'de sunulmuştur.
Tablo 1. Dört farklı yöreye ait kolemanit kristallerinin kantitatif ICP/MS analizleri.

\begin{tabular}{lll}
\hline Yöre & Eser & Yüksek \\
\hline Bigadiç & $\mathrm{Na}, \mathrm{Fe}, \mathrm{Cu}, \mathrm{Zn}, \mathrm{Sr}, \mathrm{Mo}, \mathrm{U}$ & $\mathrm{B}, \mathrm{Ca}$ \\
Kestelek & $\mathrm{Na}, \mathrm{Cu}, \mathrm{Sr}, \mathrm{Mo}, \mathrm{Ag}, \mathrm{Pb}, \mathrm{U}$ & $\mathrm{B}, \mathrm{Ca}$ \\
Espey & $\mathrm{Fe}, \mathrm{Cu}, \mathrm{Zn}, \mathrm{Sr}, \mathrm{Mo}, \mathrm{Sn}, \mathrm{W}, \mathrm{U}$ & $\mathrm{B}, \mathrm{Ca}$ \\
Hisarckk & $\mathrm{Na}, \mathrm{Cu}, \mathrm{Sr}, \mathrm{Mo}, \mathrm{U}$ & $\mathrm{B}, \mathrm{Ca}$ \\
\hline
\end{tabular}

Tablo 1'den görüldüğü gibi yapılan ICP/MS analizi sonucunda tüm yörelere ait kolemanitlerde baskın 
olarak yüksek miktarda bor (B) ve kalsiyum (Ca) elementi, eser miktarda ise birbirleriyle benzerlik gösteren elementler ( $\mathrm{Fe}, \mathrm{Na}, \mathrm{Cu}, \mathrm{Zn}, \mathrm{Sr}, \mathrm{Mo}, \mathrm{Sn}$, $\mathrm{W}, \mathrm{U})$ tespit edilmiştir. $\mathrm{Bu}$ sonuçlar da, tüm numunelerin saf olduğunu açıkça göstermektedir.

\subsection{TG-DTA analizleri}

belirlenebilmektedir. $\mathrm{Bu}$ değişimler ölçüm sırasinda elde edilen endotermik ve ekzotermik piklerin oluştukları sıcaklıklar ile açıklanır. Bu amaçla yapılan dört farklı yöreye ait saf kolemanit kristallerinin TG-DTA analizleri Şekil 7'de, grafiklerdeki piklerin analizleri ise Tablo 2'de özetlenmiştir.

Bir malzemedeki yapısal ya da kimyasal bir değişimin olduğu DTA-TG analizi ile
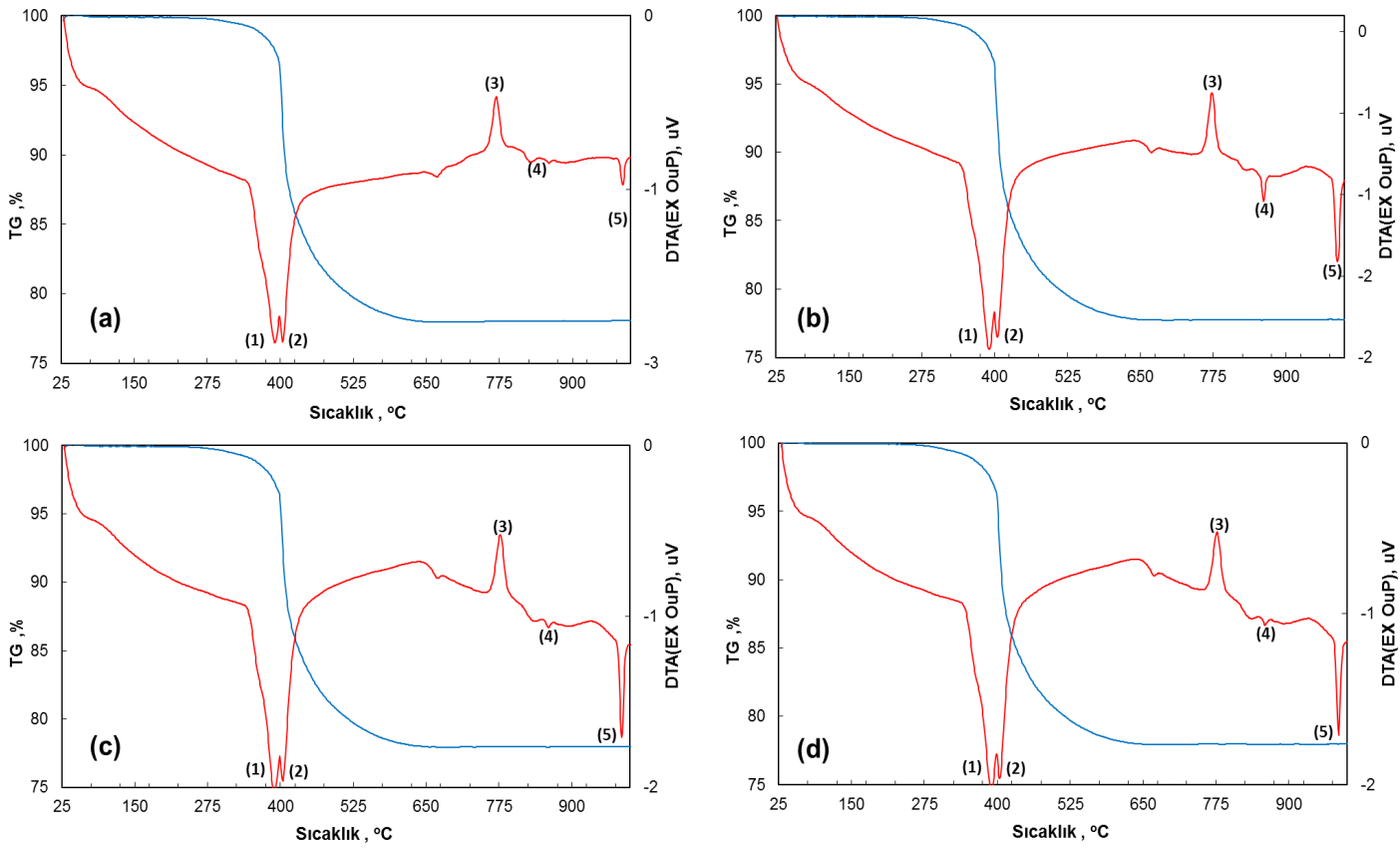

Şekil 7. (a) Bigadiç (b) Kestelek (c) Espey (d) Hisarcık kolemanit kristallerinin TG-DTA dönüşüm eğrileri.

Tablo 2. Bigadiç, Kestelek, Espey ve Hisarcık yöresi kolemanit kristallerinin TG-DTA eğrilerinin analizleri.

\begin{tabular}{|c|c|c|c|c|c|c|}
\hline Yöre & 1. Pik & 2.Pik & 3.Pik & 4.Pik & 5.Pik & $\begin{array}{c}\text { Kütle } \\
\text { değişimi,\% }\end{array}$ \\
\hline \multirow[b]{2}{*}{ Bigadiç } & $391.0^{\circ} \mathrm{C}$ & $404.2^{\circ} \mathrm{C}$ & $769.8^{\circ} \mathrm{C}$ & $866.3^{\circ} \mathrm{C}$ & $986.3^{\circ} \mathrm{C}$ & \multirow[b]{2}{*}{-21.77} \\
\hline & $\begin{array}{l}-2.3517 \\
\mu \mathrm{V} / \mathrm{mg}\end{array}$ & $\begin{array}{l}-2.3504 \\
\mu \mathrm{V} / \mathrm{mg}\end{array}$ & $\begin{array}{l}-0.58165 \\
\mu \mathrm{V} / \mathrm{mg}\end{array}$ & $\begin{array}{l}-1.0125 \\
\mu \mathrm{V} / \mathrm{mg}\end{array}$ & $\begin{array}{l}-1.2194 \\
\mu \mathrm{V} / \mathrm{mg}\end{array}$ & \\
\hline Kestelek & $\begin{array}{l}\mathbf{3 9 0 . 8}^{\circ} \mathbf{C} \\
-2.0512 \\
\mu \mathrm{V} / \mathrm{mg}\end{array}$ & $\begin{array}{l}\mathbf{4 0 4 . 5}^{\circ} \mathbf{C} \\
-1.397 \\
\mu \mathrm{V} / \mathrm{mg}\end{array}$ & $\begin{array}{l}\mathbf{7 7 2 . 9}^{\circ} \mathbf{C} \\
-0.47305 \\
\mu \mathrm{V} / \mathrm{mg}\end{array}$ & $\begin{array}{l}\mathbf{8 6 1 . 4}^{\circ} \mathbf{C} \\
-1.1397 \\
\mu \mathrm{V} / \mathrm{mg}\end{array}$ & $\begin{array}{l}\mathbf{9 8 8 . 2}^{\circ} \mathbf{C} \\
-1.5096 \\
\mu \mathrm{V} / \mathrm{mg}\end{array}$ & -22.23 \\
\hline Espey & $\begin{array}{l}\mathbf{3 9 2 . 5}^{\circ} \mathbf{C} \\
-1.6814 \\
\mu \mathrm{V} / \mathrm{mg}\end{array}$ & $\begin{array}{l}\mathbf{4 0 4 . 1}^{\circ} \mathbf{C} \\
-1.6132 \\
\mu \mathrm{V} / \mathrm{mg}\end{array}$ & $\begin{array}{l}\mathbf{7 6 5 . 2 ^ { \circ }} \mathbf{C} \\
-0.182 \\
\mu \mathrm{V} / \mathrm{mg}\end{array}$ & $\begin{array}{l}\mathbf{8 6 0 . 7}^{\circ} \mathbf{C} \\
-0.7139 \\
\mu \mathrm{V} / \mathrm{mg}\end{array}$ & $\begin{array}{l}\mathbf{9 8 7 . 7}^{\circ} \mathbf{C} \\
-0.96093 \\
\mu \mathrm{V} / \mathrm{mg}\end{array}$ & -21.92 \\
\hline Hisarcık & $\begin{array}{l}\mathbf{3 8 9 . 8}^{\circ} \mathbf{C} \\
-2.025 \\
\mu \mathrm{V} / \mathrm{mg}\end{array}$ & $\begin{array}{l}\mathbf{4 0 4 . 1}^{\circ} \mathbf{C} \\
-1.9662 \\
\mu \mathrm{V} / \mathrm{mg}\end{array}$ & $\begin{array}{l}\mathbf{7 7 7 . 0}^{\circ} \mathbf{C} \\
-0.52167 \\
\mu \mathrm{V} / \mathrm{mg}\end{array}$ & $\begin{array}{l}\mathbf{8 5 9 . 8}^{\circ} \mathbf{C} \\
-1.0675 \\
\mu \mathrm{V} / \mathrm{mg}\end{array}$ & $\begin{array}{l}\mathbf{9 8 5 . 5}^{\circ} \mathbf{C} \\
-1.7093 \\
\mu \mathrm{V} / \mathrm{mg}\end{array}$ & -21.82 \\
\hline
\end{tabular}


Şekil 7 ve Tablo 2 incelendiğinde; tüm kolemanit numunelerinde endotermik reaksiyonun olduğu, termal ayrışmanın gerçekleştiğ $i \sim 350^{\circ} \mathrm{C}-450^{\circ} \mathrm{C}$ 'de hızlı su kaybına uğramışlardır. DTA eğrilerine bakıldığ 1 zaman $\sim 389^{\circ} \mathrm{C}$ ve $404^{\circ} \mathrm{C}$ aralığında keskin piklerin olduğu görülmüştür. $\mathrm{Bu}$ sicaklık aralığında kolemanitin yapısındaki 5 mol suyu (yaklaşık 1/3 oranında suyunu) kaybetmiştir (Gündoğmaz ve Güler 2008).

Hızlı su kaybı, kristal matrisinde oluşan düzensiz gerilmeler yapıda genişlemeye neden olur böylelikle bu iç gerilmeler sonucu oluşan kırıklarda sıcaklık artışı ile sonradan oluşacak olan kristal dönüşümüne imkan sağlar (Celik ve Suner, 1995). Bigadiç, Kestelek, Espey ve Hisarcık için ekzotermik reaksiyonu ifade eden ve kristallenmenin başladığı sıcaklıklar sırasıyla; $769.8^{\circ} \mathrm{C}, 772.9^{\circ} \mathrm{C}, 765.2^{\circ} \mathrm{C}$ ve $777.0^{\circ} \mathrm{C}$ 'dir. $\mathrm{Bu}$ sicaklıklarda yapısal hidroksil grupları $(-\mathrm{OH})$, ve su ve borat zincirleri (Waclawska, 1988) arasındaki hidrojen bağlarının kırılmasına atfedilmiştir. Numuneler $\left(987.7^{\circ} \mathrm{C}, 988.2^{\circ} \mathrm{C}\right.$ ve $985.5^{\circ} \mathrm{C}$ de
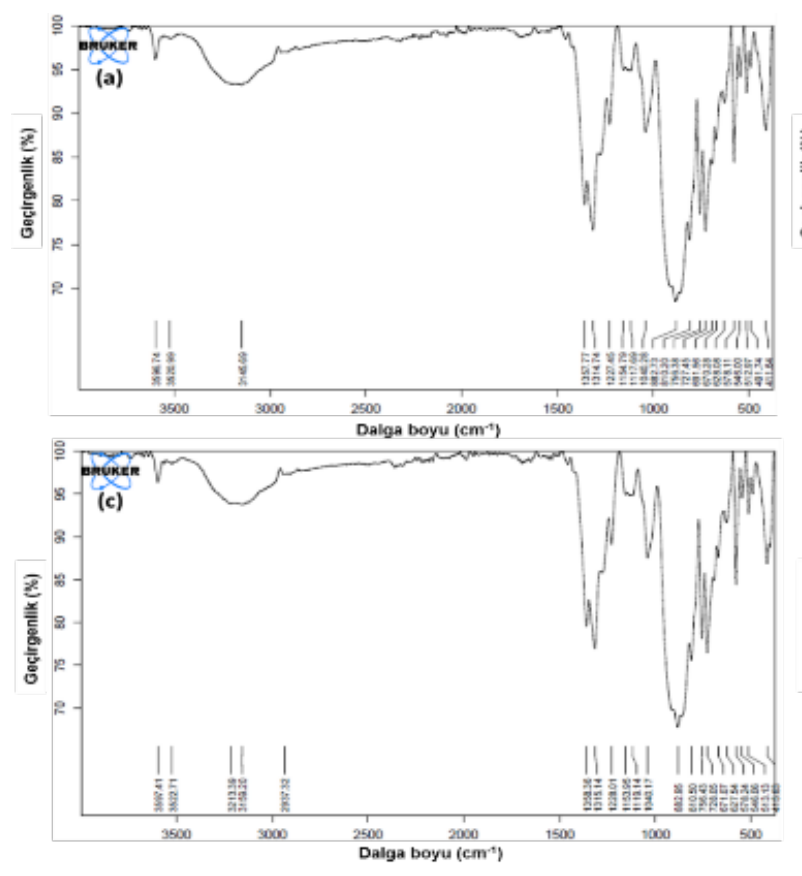

ikinci bir endotermik reaksiyon ile eriyip, amorf yapıya dönüşmüşlerdir.

Termo Gravimetrik Analiz (TG) eğrisi ile artan ortam sıcaklığına bağlı olarak tüm kolemanit numunelerinin kütle değişimini termobalans ile sürekli olarak ölçülmüştür. Numunelerdeki nem ve uçucu madde miktarını yaklaşık \%21.94 kütle kaybı değişimi olarak vermektedir.

\subsection{FT-IR analizleri}

Kızılötesi (IR) absorbsiyon spektroskopisi (FT-IR) 1şığın infrared (kızıl ötesi 1şı1nlar) yoğunluğuna karşı dalga sayısını ölçen, bir tür titreşim spektroskopisidir. Ölçümlerde, molekülün titreşim hareketleri kızılötesi 1şınlar tarafindan soğurulmaktadır. $\mathrm{Bu}$ analiz, katı kolemanit numunelerinin IR aktif molekül özellikleri ile moleküler bağ karakterizasyonu, yapısındaki fonksiyonel grupların ve bağların durumunun saptanması amacıyla yapılmıştır. Şekil 8'de dört farklı yöreye ait kolemanitlerin FT-IR analizleri sunulmuştur.

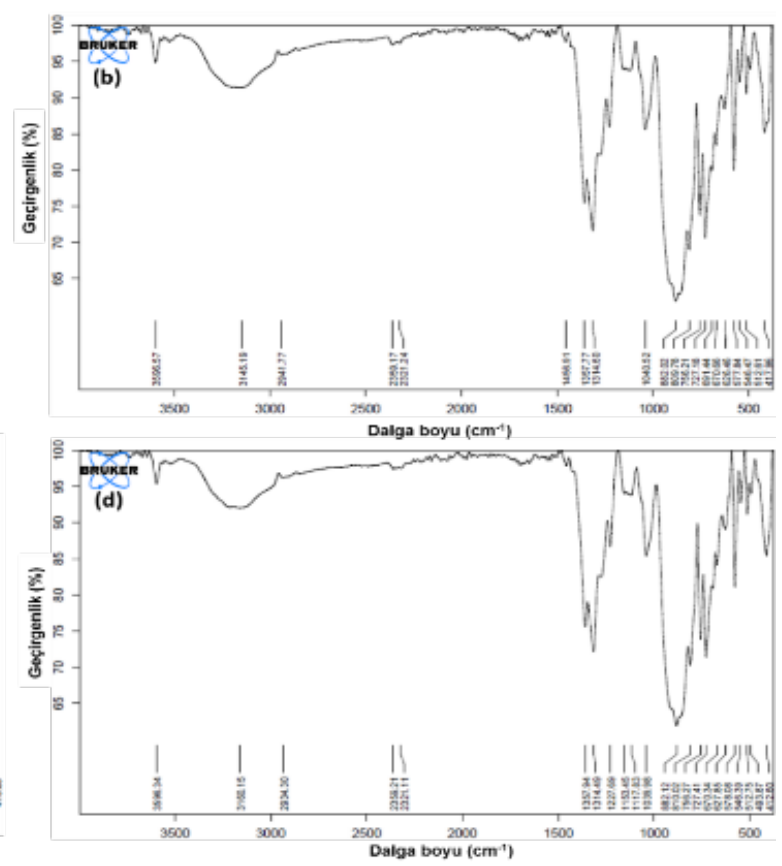

Şekil 8. (a) Bigadiç (b) Kestelek (c) Espey (d) Hisarcık kolemanit kristallerinin FT-IR analizleri.

Şekil 8 incelendiğinde, her bir yöreye ait kolemanit kristallerinin saf olup, benzer IR spektrumlarına sahip olduğu görülmüsşür. $3597-3522 \mathrm{~cm}^{-1}$ 'de hidrojen bağlı O-H gerilmesi, 3213-3159 cm-1 'de ikinci bir $\mathrm{O}-\mathrm{H}$ bandı tespit edilmiştir.

$\mathrm{Bu}$ konu ile ilgili literatür de yapılan FT-IR yorumlarında ise; $1322-2355 \mathrm{~cm}^{-1}$ pikleri $\mathrm{BO}_{2}{ }^{-}$ grubunun B-O asimetrik gerilme titreşimine ait olduğu, 1314, 819, $751 \mathrm{~cm}^{-1}$ pikleri sırası ile $\mathrm{BO}_{3}^{-3}$ grubuna ait asimetrik gerilme, simetrik eğilme titreşimlerini ifade ettiği, karakteristik $\mathrm{O}-\mathrm{H}$ grubuna ait bantların ise $638,3534 \mathrm{~cm}^{-1}$ eğilme ve gerilme titreşimlerine ait olduğunu bildirmişlerdir (Frost vd., 2016; Ternane vd., 2002, Gündoğmaz ve Güler, 2008). 


\section{Tartışma ve sonuçlar}

$\mathrm{Bu}$ çalışma ile dört farklı yöreye ait saf kolemanit kristallerine detaylı karakterizasyon çalışmaları yapılmıştır. Elde edilen sonuçlar; öncelikle farklı yöreler kendi arasında, sonrasında ise aynı yöreye ait kolemanitler cevher ve kristal olarak kıyaslanmıştır. Bu kapsamda elde edilen sonuçlara göre;

- XRD mineralojik analizleri ile dört farklı yöreye ait kolemanit kristallerinin saf olduğunu ve herhangi bir istenmeyen (gang) minerali içermediği saptanmıştır.

- ICP/MS kimyasal analizleri ile tüm kolemanit kristalleri detaylı olarak tanımlanmış, numunelerde yüksek miktarda bor ve kalsiyum (B, Ca) elementi, eser miktarda ise numuneler arasinda benzerlik gösteren elementler olan $\mathrm{Fe}, \mathrm{Na}, \mathrm{Cu}, \mathrm{Zn}, \mathrm{Sr}, \mathrm{Mo}, \mathrm{Sn}$, $\mathrm{W}, \mathrm{U}$ tespit edilmiştir.

- TG/DTA analizleri ile belirlenen termal özellikleri incelendiğinde; tüm kolemanit numunelerinde endotermik reaksiyonun olduğu, $\sim 350^{\circ} \mathrm{C}-450^{\circ} \mathrm{C}$ 'de hızlı su kaybına uğrayarak termal ayrışmanın gerçekleştiğini göstermiştir. Ayrıca, tüm kolemanit numunelerinin $389^{\circ} \mathrm{C}$ ve $404^{\circ} \mathrm{C}$ aralığında yapısındaki 5 mol suyu kaybettiği tespit edilmiştir. Bigadiç, Kestelek, Espey ve Hisarcık yöreleri kolemanitleri için ekzotermik reaksiyonu ifade eden ve kristallenmenin başladığ ${ }^{\circ}$ sıcaklıkların sirasiyla; $769.8^{\circ} \mathrm{C}, \quad 772.9^{\circ} \mathrm{C}, \quad 765.2^{\circ} \mathrm{C}$ ve $777.0^{\circ} \mathrm{C}$ olduğu ve $987.7^{\circ} \mathrm{C}, 988.2^{\circ} \mathrm{C}$ ve $985.5^{\circ} \mathrm{C}$ 'de ise ikinci bir endotermik reaksiyon ile eriyip, amorf yapıya dönüştükleri tespit edilmiştir. TG analiz sonuçları incelendiğinde ise; artan ortam sıcaklığına bağlı olarak her bir numunenin yaklaşık \%21.94 kütle kaybına (nem ve uçucu madde) uğradığını göstermiştir.

- $\quad$ FT-IR analizleri incelendiğinde her bir yöreye ait kolemanit kristallerinin benzer IR spektrumlarına sahip olduğu, $3597-3522 \mathrm{~cm}^{-1}$ 'de hidrojen bağlı O-H gerilmesi, 3213-3159 $\mathrm{cm}^{-1}$ 'de ikinci bir O-H bandının olduğu tespit edilmiştir.

Genel olarak dört farklı yöreye ait saf kolemanit kristallerinden elde edilen tüm sonuçlar değerlendirildiğinde, fiziksel özellikleri açısından aralarında farklılıklar olmasına rağmen, yapılan karakterizasyon çalışmalarında benzer özellik gösterdikleri, aralarında belirgin bir farklılığın olmadığ1 görülmüştür. Cevher minerali ile saf kristal arasındaki tek farklılı̆̆ın ise; kolemanit cevherlerinde bulunduğu yörede baskın olan gang minerallerinden ve jeokimyasal süreçlerden kaynaklandığı anlaşılmıştır.

\section{Teşekkür}

Yazar, bu çalışmanın gerçekleşmesinde maddi destek sağlayan İstanbul Üniversitesi Bilimsel Araştırma Projeleri Birimi'ne (Proje No: 42265); Çalışmanın tüm aşamasındaki bilimsel yönlendirmeleri ve katkıları için danışmanları Prof. Dr. Mehmet Sabri Çelik ve Prof. Dr. Orhan Özdemir'e ayrica makalenin inceleme ve değerlendirme aşamasında yapmış oldukları katkılardan dolayı editör ve hakem/hakemlere teşekkür eder.

\section{Kaynaklar}

Bayca, S. U., Kocan F. and Y. Abali (2014). Dissolution of colemanite process waste in oxalic acid solutions. Environmental Progress \& Sustainable Energy, 33, 1111-1116.

Bilgiç, M. ve Dayık, M. (2013), Borun özellikleri ve tekstil endüstrisinde kullanımıyla sağladığı avantajlar. Electronic Journal of Vehicle Technologies/Tasit Teknolojileri Elektronik Dergisi, 7.

Celik, M. S. and Suner, F. (1995). A Thermodynamic analysis of the decrepitation process. Thermochimica Acta, 254, 167-174.

Colak, M., Helvaci, C. and Maggetti, M. (2000). Saponite from the Emet colemanite mines, Kutahya, Turkey. Clays and Clay Minerals, 48, 409-423.

Çelikoyan Kuşkay, B. ve Bulutcu, A. N. (2010). Kolemanitten yeni bir yöntemle borik asit üretim prosesinin geliştirilmesi. ITÜ Dergisi/d, 9, 1526.

Demirtaş, A. (2006). Bor bileşikleri ve tarımda kullanımı. Atatürk Üniversitesi Ziraat Fakültesi Dergisi, 37, 111-115.

Dill, H. G., Kaufhold, S. and Helvaci, C. (2015). The physical-chemical regime of argillaceous interseam sediments in the Emet borate district, Turkey: A transition from non-metallic volcanosedimentary to metallic epithermal deposits. Journal of Geochemical Exploration, 156, 44-60.

Erdem, N. İ. (2010). Emet-Hisarclk (Kütahya) bor yataklanmasin oluşturan bor minerallerinin dağllımları, jeokimyası ve oluşum ortamlarının 
incelenmesi. Kocaeli Üniversitesi, Fen Bilimleri Enstitüsü, Kocaeli.

Erdoğan, Y., Aksu, M., Demirbaş, A. and Abalı, Y. (1998). Analyses of boronic ores and sludges and solubilities of boron minerals in $\mathrm{CO}_{2}$-saturated water. Resources, Conservation and Recycling, 24, 275-283.

Eti Maden İşletmeleri Genel Müdürlüğü. (2016). Bor Sektör Raporu. Strateji Geliştirme Dairesi Başkanlığı.

Eti Maden İşletmeleri Genel Müdürlüğü, S. G. D. B. (2009). Stratejik Plan (2009-2013).

Frost, R. L., Scholz R., Ruan, X. and Lima R. M. F. (2016). Thermal analysis and infrared emission spectroscopy of the borate mineral colemanite (CaB3O4 (OH) 3. H2O). Journal of Thermal Analysis and Calorimetry, 124, 131-135.

Gündoğmaz, G. ve Güler, H. (2008). Kolemanit ve diamonyum fosfatın farklı yüksek sicaklıklarda oluşturduğu ürünlerin yapılarının karakterizasyonu. Ballkesir Üniversitesi Fen Bilimleri Enstitüsü Dergisi, 10, 3-18.

Güyagüler, T. (2001). Türkiye Bor Potansiyeli. 4. Endüstriyel Hammaddeler Sempozyumu (ss. 1827).

Habashi, F. (1997). Handbook of Extractive Metallurgy. WILEYVCH, Germany, 4, (pp. 1985-2026).

Helvaci, C. (1977). Geology, mineralogy and borate deposites. University of Nottingham.

Helvacı, C. (2003). Türkiye borat yatakları: jeolojik konum, mineraloji ve bor politikası. Balıkesir Üniversitesi Fen Bilimleri Enstitüsü Dergisi 5(1), 4-41.

Helvacı, C. (2004a). Türkiye borat yatakları jeolojik konumu, ekonomik önemi ve bor politikası. Balıkesir Üniversitesi Fen Bilimleri Enstitüsü Dergisi, 5, 4-41.

Helvacı, C. (2004b). Türkiye Borat Yatakları: Jeolojik Konumu, Ekonomik Önemi ve Bor Politikası 5. Endüstriyel Hammaddeler Sempozyumu, İmir, Türkiye.

Helvacı, C. (2005). Batı Anadolu'da arsenik ile bor mineralleri ilişkisi ve sağlığa etkileri, 1. Tıbb̂ Jeoloji Sempozyumu, MTA (ss. 74-88).

Helvacı, C. (2008). Doğada bor ve arsenik elementlerin ilişkisi (Relationships between boron and arsenic elements in nature). In Uluslararasi Katılıml Tibbi Jeoloji Sempozyumu (ss. 116-117).
Helvacı, C. (2015). Bor yataklarının genel değerlendirilmesi ve gelecek öngörüsü. Madencilik ve Yer Bilimleri Dergisi.

Helvaci, C. and Orti F. (1998). Sedimentology and diagenesis of miocene colemanite-ulexite deposits (Western Anatolia, Turkey). Journal of Sedimentary Research, 68, 1021-1033.

Kalafatoğlu, İ. E. ve Örs, S. N. (2003). 21. yüzy1lda bor teknolojileri ve uygulamaları. Balıkesir Üniversitesi Fen Bilimleri Enstitüsü Dergisi, 5, 59-71.

Kar, Y., Şen, N. and Demirbaş A. (2006). Boron minerals in Turkey, their application areas and importance for the country's economy. Minerals \& Energy-Raw Materials Report, 20, 2-10.

Karaaağlığlu I. E., Özyildirim Ö., Karatas D., Özdemir O., Karakas F., Boylu F. and Celik, M. S. (2016). How gangue minerals in colemanite ore affect arsenic removal during its calcination. In 15th International Mineral Processing Symposium (ss. 790-800). Istanbul-Turkey, October 19-21, 2016.

Kılınç, E., Mordoğan H. ve Tanrıverdi M. (2001). Bor minerallerinin önemi, potansiyeli, üretimi ve ekonomisi. Endüstriyel Hammaddeler Sетроzуити (ss. 18-19).

Poslu, K. ve Arslan İ. (1995). Dünya bor mineralleri ve bileşikleri üretiminde Türkiye'nin yeri. Endüstriyel Hammaddeler Sempozyumu (ss. 3334).

Ternane, R., Cohen-Adad M. T., Panczer, G., Goutaudier, C., Kbir-Ariguib N., Trabelsi-Ayedi M., Florian and Massiot, P. (2002). Introduction of boron in hydroxyapatite: synthesis and structural characterization. Journal of Alloys and Compounds, 333, 62-71. https://doi.org/10.1016/S0925-8388(01)015584.

Waclawska, I.S.L., Paulik, J. and Paulik, F. (1988). Thermal decomposition of colemanite. Thermochim Acta, 307-318 https://doi.org/10.1016/0040-6031(88)87276-9.

Woods, W. G. (1994). An introduction to boron: history, sources, uses, and chemistry. Environmental Health Perspectives, 102, 5-11.

Yigitbasioglu, H. (2014). Türkiye için önemli bir maden: Bor. Coğrafi Bilimler Dergisi, 2, 13-25.

Yildiz, Ö. (2004). The effect of heat treatment on colemanite processing: a ceramics application. Powder Technology, 142, 7-12. 